\title{
RAZA Y PROYECTO NACIONAL EN \\ CUANDO LOS GUAYACANES FLORECÍAN DE \\ NELSON ESTUPIÑÁN BASS
}

\author{
POR \\ M'BARE N'GOM \\ Morgan State University
}

Publicada en 1954, Cuando los guayacanes florecían de Nelson Estupiñán Bass (Súa, Ecuador 1912), es una novela que se podría calificar de gigantesco fresco socio-histórico del Ecuador en los albores del siglo XX. En esta primera novela suya, Estupiñán Bass nos sitúa en un universo muy específico de la geografía ecuatoriana: Esmeraldas, en un momento determinado de su historia: la revolución liberal conchista de principios del siglo $\mathrm{XX}$.

Nuestro propósito en este trabajo es examinar las distintas estrategias narrativas de las que se vale el autor de Cuando los guayacanes florecian (en adelante CLGF) para instalar por un lado, un texto de denuncia social; $y$, por el otro lado, mostrar el carácter excluyente del Proyecto Nacional nacido a raíz de la independencia del país, así como la apropiación y falsificación de la Historia Nacional del Ecuador. Además, resaltaremos los aspectos que enmarcan el texto de Estupiñán Bass dentro de lo que Richard L. Jackson (1986 y 1988) llama "discurso humanista".

La anécdota de Cuando los guayacanes florecian gira en torno al asesinato del dirigente liberal el general Eloy Alfaro ocurrido en 1912. Para asegurar la supervivencia del liberalismo, uno de sus seguidores, el capitán Pincay, les cuenta a un grupo de campesinos de Esmeraldas las circunstancias brutales de la muerte del general Alfaro y de sus simpatizantes en Quito. El capitán Pincay se aprovecha de la situación para reclutar un ejército revolucionario con vistas a vengar la muerte del dirigente liberal y, de paso, cambiar la situación del país. Promete la libertad a todos los campesinos concertados que se alisten.

La novela cuenta las andanzas de los libertos Juan Cagua, Pedro Tamayo, Alberto Morcú y otros, embarcados en una revolución que se supone debía liberarlos y, de paso, trasladarlos de la periferia a una posición central en cuanto a visibilidad social, económica y política. Pero la revolución cambia de rumbo. Y muy pronto, no sólo se dan cuenta de ello, sino también de que la revolución lleva dentro de sí los gérmenes de su propia destrucción, ya que algunos de los protagonistas se habían convertido en los peores enemigos de la misma.

Richard Jackson (1988) define el humanismo, dentro del contexto que nos ocupa aquí, como, "an attitude of concern for the welfare and dignity of human beings, especially the 'marginal' ones, and for the problems that beset them in this life" (XIII). Es, pues, un discurso que expresa una preocupación por la condición humana y que denuncia la opresión 
socio-económica y política de los grupos sociales periféricos, al tiempo que busca medios para superarla. En este sentido, se puede afirmar que es un discurso incluyente que trasciende las barreras étnicas y somáticas. Su objetivo último es, por un lado, liberar a los marginados, negros e indígenas, social y económicamente, y por el otro, incorporarlos a la construcción del proyecto nacional ecuatoriano.

Esa actitud de denuncia de la opresión que sufrían los sectores étnicos marginados dentro del proyecto nacional de varios países hispanoamericanos, pese a su activa y decisiva participación en las fases decisivas de la Historia Nacional, guerras de independencia, guerras civiles, revoluciones, se puede rastrear en textos y autores tan diversos como Changó, el gran putas (1985), del colombiano Manuel Zapata Olivella, Juyungo (1943), del ecuatoriano Adalberto Ortiz, y Chombo (1981) del panameño Cubena por citar algunos nombres y obras.

El texto de Estupiñán Bass se enmarca dentro del proyecto cultural de la llamada generación del 30, cuyo discurso expone desde una perspectiva interna y plural las contradicciones del Proyecto Nacional ecuatoriano. Herederos del discurso de denuncia social del proyecto cultural del llamado Grupo de Guayaquil, los escritores de la generación del 30 actuaron desde una plataforma de compromiso social.' Su discurso, marcado por un fuerte realismo social, es incluyente y nacionalista, ya que procura explorar e incorporar la diversidad y riqueza de la cultura nacional ecuatoriana dentro de un proyecto histórico, social y político que hubiera debido de ser común a todos. Pero fue, por encima de todos un discurso de vigorosa protesta y denuncia contra el secuestro de la realidad del Ecuador. Este es el contexto socio-historico y literario en el que se enmarca la práctica textual de Nelson Estupiñán Bass. Un proyecto cultural que intenta reflejar el país real en su diversidad, el del negro, del indio, del montubio, del cholo y, de paso, denunciar lo que Michael Handelsman llama:

los silencios de las diferentes historias oficiales (y de la crítica literaria, también) que han mantenido al negro en una periferia nacional durante los últimos cinco siglos en el Ecuador [...] ("Ubicando la literatura" 43).

El proyecto cultural de Nelson Estupiñán Bass aboga por un país plurinacional. En este sentido, nos propone, pues, un discurso incluyente donde la construcción de la nacionalidad ya no se apoya, en la apropiación y monopolización de dicha realidad por una minoría, sino más bien en la aportación de todas las etnias y actores sociales que configuran la nacionalidad ecuatoriana.

En el Ecuador, la ideología nacionalista que nació tras la independencia en 1830, declaró la nación ecuatoriana como mestiza (Whitten 196). Pero la realidad era muy diferente, porque el mestizaje tal como lo concebían los padres de la nación, significaba ni más ni menos que blanqueamiento. La ideología nacionalista ponía más énfasis hacia el "lado claro del paradigma del mestizaje" (Whitten 196), cuando la nación era, en realidad,

\footnotetext{
' El Grupo de Guayaquil, cuyos textos aparecen a partir de la segunda década de este siglo, estaba integrado por los escritores José de la Cuadra, Alfredo Parejo Diezcanseco, Joaquín Gallegos Lara, Enrique Gil Gilbert y Demetrio Aguilera, a quienes se apodaba "los cinco como un puño".
} 
un ente plurinacional y multiétnico. El Proyecto Nacional ecuatoriano partía, pues, de una plataforma excluyente porque los no-blancos y los no-mestizos, es decir, los indios y los negros quedaban al margen del mismo. Por lo tanto, tras esa ideología nacionalista se escondía una doble percepción y representación de la realidad. Por un lado, ese discurso se apoyaba en la abrogación de la etnia, es decir, la negación del carácter multiétnico del país, y por el otro, resaltaba la supremacía de la raza blanca. Ello dio nacimiento a una realidad que se articulaba en torno a unas oposiciones binarias y relaciones asimétricas que afectaban, y siguen afectando, en muchos casos, todos los aspectos de la vida nacional en el Ecuador.

El Proyecto Nacional ecuatoriano creó, pues, una semantización del mapa (geográfico, histórico, social, económico y político) del Ecuador que polarizó a los distintos actores sociales por medio de un discurso de división binaria. De ello resultó la fragmentación del país y su enajenación consigo mismo, instalando, de ese modo, dos visiones, dos países: el país oficial y visible, y el país periférico e invisible. Michael Handelsman, afirma al respecto que:

la supuesta aceptación del negro ecuatoriano como componente integral del contexto nacional ha sido más bien un "simulacro". En lo que respecta a los afroecuatorianos, el clivaje que existe entre lo que se dice (no hay racismo, por ejemplo) y lo que se vive (la marginalidad) es demasiado patente para seguir aferrándose a un concepto utópico de mestizaje [...] ("Ubicando la literatura" 42).

Cuando los guayacanes florecian refleja ese discurso de fragmentación por medio de los contrastes asimétricos que recorren todo el universo de la novela y que se manifiestan bajo diversas formas. En las primeras páginas de la novela las dos visiones del Ecuador se hacen patentes cuando el capitán Pincay anuncia la muerte violenta del general Eloy Alfaro a un grupo de campesinos esmeraldeños. La reacción es inmediata porque el capitán Pincay acusa a los conservadores, "enemigos que se han bebido, como chacales, la sangre de mi general" (CLGF 77); mientras los liberales aparecen como los defensores de la libertad y de la patria. La division es también geográfica con ribetes étnicos oponiendo los costeños a los serranos; y aquéllos, tienen que, "castigar con mano de hierro a los serranos que mataron a los generales costeños" (CLGF 80).

Ese antagonismo binario reaparece cuando un coronel del ejército gubernamental les comunica a unos campesinos que interrogaba que venía a traerles la libertad y a protegerlos. Y lo mismo les había dicho el capitán Pincay. En este caso también, surgen las dicotomías porque para los campesinos: "el capitán Pincay era costeño. El coronel era serrano. El capitán atraía a todos con cariño. El coronel era un déspota"(CLGF 96).

Dentro de este orden de ideas, Esmeraldas, según el coronel, es, "Tierra maldita que apesta, tierra de negros salvajes, bubosos y palúdicos"(CLGF 95 ); en contraste con el resto del país (entiéndase Quito) que simboliza la civilización. Vuelve a surgir aquí, la noción sarmientina de civilización vs. barbarie, la cual como ideología social, política y de desarrollo, marginaba al país profundo y real.

En este discurso nacional de fragmentación y de estructuras binarias rígidas e inamovibles, el polo positivo (civilizado y civilizador) corresponde a las clases dirigentes 
blancas, mientras el lado débil y negativo del eslabón está ocupado por los periféricos de ese universo, es decir, los negros, los indígenas y los mestizos, en menor medida.

La independencia del Ecuador no trajo la libertad y el bienestar para toda la ciudadanía, ya que, como escribe Argentina Chiriboga (1992):

[...] tras la independencia, los terratenientes conservaron los latifundios y asumieron el poder político en el Ecuador, como en la mayoría de los países americanos. Los beneficios de la independencia constituyeron para la oligarquía el establecimiento de sus relaciones con Inglaterra $[\ldots]$ (133).

La realidad poscolonial ecuatoriana era, pues, una réplica, en un contexto nacional y soberano, de las estructuras sociopolíticas y económicas de la situación colonial. La única diferencia radicaba en el hecho de que la antigua aristocracia colonial había sido sustituida por una oligarquía nacional aliada con el capital extranjero. En la novela, el grupo opresor está representado por individuos como Don Rodrigo Medrano de Pereira y Quezada, Don Luis Toapanta, que se han aprovechado de la revolución para construir y consolidar sus fortunas, y otros como el joven "Pompo", futuro yerno de Don Rodrigo y el sargento Miguel Baguí, cuyo propósito es aprovecharse de la revolución para edificar nuevas fortunas e integrar el grupo de los dominantes. En este sentido, la revolución, como constata con mucha amargura el Capitán Pincay en su lecho de muerte, había sido traicionada:

A la sombra del nombre de Alfaro, ¡cómo se están levantando las fortunas! ¡Las fortunas de la revolución, las fortunas que surgen ensangrentadas, manchadas con la sangre de los incautos que confían todavía en que estamos peleando por un ideal! ¡Casi todos los jefes son unos bandidos! $¡$ Maldita sea! $¡ Y$ haberme enfermado de esta enfermedad incurable solamente para ser un escalón de ladrones, y nada más [...]! (CLGF 166)

Los grupos periféricos no sólo han interiorizado estas profundas desigualdades sociopolíticas y económicas, sino que han asumido también su situación de marginación y de invisibilidad. Así lo expresa uno de los personajes llamado el Curandero cuando dice: "el pobre no debe pensar" (172). En otras palabras, el discurso nacionalista estableció una estructura de "otredad" para acomodar a los marginados que la aceptan y asumen como algo negativo, feo y diabólico, pero al fin y al cabo, la aceptan. Cipriano, el joven sirviente negro del terrateniente Don Rodrigo Medrano de Pereira y Quezada, es quizás uno de los ejemplos más patentes de esa actitud de rechazo de la raza propia como algo negativo. Cuando le dicen a Cipriano que Mercedes, la hija del amo, está enamorada de él, su reacción es la siguiente:

¿Qué quería? ¿Qué podía aspirar él de ella? ¡Sí! Ya lo comprendía: ¡Estaba enamorado! Si acaso hubiera sido blanco, la cosa sería distinta; pero siendo negro estaba de por medio, como una gruesa e insalvable muralla, el color. ¿ Por qué había tenido la mala suerte de nacer negro? (CLGF 178).

Para Cipriano y muchos otros, el camino hacia la libertad pasa, muchas veces, por el rechazo de la realidad somática y de los valores étnicos propios, lo cual denota un profundo y desgarrador conflico personal, psicológico y cultural. 
El mundo que aparece en Cuando los guayacanes ... y en otros textos del mismo autor están marcados por la injusticia, los abusos, la degradación humana y la violación de los derechos fundamentales, entre otros. Es una realidad alienada por la violencia en todos sus sentidos.

La violencia recorre el universo de la novela de principio a fin, pese a que se abra con una nota optimista:

En todos los cerros los guayacanes celebraban su fiesta de oro [...] daban la impresión de vocear por todos los ámbitos su alegría por la entrada de las aguas. Toda la tierra parecía una hermosa litografía, mojada aun por la tinta resplandeciente de los talleres. Era cuando los guayacanes florecían (CLGF 76).

La novela comienza con la narración de un acto violento: el asesinato del dirigente liberal Eloy Alfaro y de sus seguidores y se cierra con la misma nota: la muerte por disparos de la policía del concierto Alberto Morcú, el cual, junto con otros, intentaba escapar de esa versión moderna e institucionalizada de la esclavitud que es el concertaje. Entre estos dos polos, hay todo un universo mediatizado por distintas formas de violencia. Empezando por la revolución conchista cuyo propósito era luchar contra las injusticias y los abusos, acaba sucumbiendo a la realidad y surmergiéndose en el ciclo de la violencia. Hasta los protagonistas de la misma, como Juan Cagua, denuncian este hecho: "Me parece que estamos manchando la causa con la sangre de los inocentes" (CLGF 138); o el narrador cuando observa:

La pampa continuaba llena de cadáveres. En algunos sitios la sangre estancada había formado charcos claramente visibles (CLGF 111).

Las fuerzas facciosas habían obscurecido casi completamente el llano, y los machetes vengativos, sedientos de sangre, empezaban a derribar las primeras cabezas. [...]. Los hilillos escarlatas fueron haciéndose brazos; los brazos desembocaron en esteros; y los esteros se juntaron para formar un río (CLGF 108).

La revolución fracasa porque, como apunta otro de los protagonistas, “[...] eso no fue una revolución. Eso fue una ola de criminalidad nada más” (CLGF 268).

El concertaje es otra manifestación de la violencia o, mejor dicho, de la explotación, agresión, mutilación y humillación del cuerpo de los periféricos. Cuando la esclavitud fue abolida en el Ecuador en 1851, los antiguos esclavos se convirtieron en asalariados, creando de esta forma una nueva realidad socioeconómica. Pero muy pronto, cayeron presos de una nueva forma de esclavitud: el concertaje, un ciclo vicioso de endeudamiento que atrapa y sume al negro y al indígena en una nueva forma de esclavitud ya que la deuda contraída se transmite de padre a hijo, y así por generaciones hasta que quede saldada, lo cual no ocurría casi nunca. El concertaje es una estructura que quebranta la voluntad del individuo que interioriza el abuso y, en muchos casos, acepta su situación como su sino. El concertaje como instrumento de explotación, degrada y humilla al individuo, al que se deshumaniza hasta reducirlo al estado de bestia y, en última instancia, en objeto. Así se refleja en la actitud sumisa y temerosa de los conciertos ante la autoridad que el narrador describe así: 
Llegaron tímidamente, con un temor de siglos. Temor acumulado desde su niñez, desde cuando empezaron a tener uso de razón, o tal vez desde más atrás de lo que pudieran acordarse, que fue desde cuando les dijeron que eran conciertos de doña Jacinta hasta la completa cancelación de las deudas de los padres muertos. Temor enraizado en las profundidades del alma estos esclavos cuando los padres, al borde de la tumba, los entregaron a la "viuda" doña Jacinta por "tinta y papel" (CLGF 78).

El concertaje no sólo es una de las máximas formas de impune agresión al cuerpo de los periféricos, sino que es también uno de los exponentes más evidentes de la fragmentación y desarticulación de la nación ecuatoriana. En este sentido, el concertaje se encuadra dentro de la estructura de violencia vertical, social y directa que ha marcado la realidad ecuatoriana, y cuya presencia es una constante en el texto de Estupiñán Bass, y en el proyecto discursivo de la generación del 30. A tal efecto, Miguel Donoso Pareja observa:

La violencia popular es, siempre, una contestación, una respuesta - precisamente - a la violencia del poder que nace y muere en la agresión [...]. Las clases dominantes, por un lado, violentando constantemente al pueblo, y éste, por el otro, respondiendo a esa agresión (10).

En Cuando los guayacanes florecían, E. Bass textualiza y tematiza la violencia que pasa a ocupar un lugar central en la novela.

Estructuralmente, la novela está dividida en 15 capítulos con títulos cada uno. No hay héroe individual, sino un héroe colectivo. El terrateniente y gobernador de Esmeraldas, don Rodrigo Medrano de Pereira y Quezada, "hombre de sangre azul y cuyos antepasados [...] habían venido de España" (CLGF 158), casado con Doña Emperatriz Espinosa Tejada de Acevedo de las Vegas, representa a un grupo privilegiado y poderoso que domina y explota a los periféricos de ese universo, negros e indios, a quienes inculcan y hunden cada vez más en lo que Angelina Pollack-Eltz (1976) llama la "cultura de la pobreza". Es un integrante de un grupo que se aferra a unos privilegios heredados que ya deberían haber sido caducos en un estado plurinacional como el Ecuador, por citar el ejemplo que nos ocupa aquí.

En el otro lado del espectro están personajes como Juan Cagua, Alberto Morcú y Pedro Tamayo que integran una categoría social oprimida, explotada y despreciada. El narrador apunta:

Era la gente de ellos. Era la gente brava e indomable, [...]. Era la gente de los ríos, de las llanuras inmensas y despobladas de adentro de las montañas, de las tierras desligadas por completo del resto de la Patria [...] (CLGF 97).

Sus experiencias no son solitarias ni aisladas, sino que representan las miles y miles de seres periféricos atrapados en el engranaje de esa realidad mediatizada, alterada e inauténtica. Son individuos a los que las estructuras de ese universo, así como el discurso que lo rige, el de los terratenientes, de los representantes de la nación, han ido sumiendo a lo largo de los años en una actitud de conformismo y de fatalismo, como se trasparenta en las reflexiones de varios de los personajes: 
-Eso es puro cuento - argumentó Juan Cagua, tomando un trago-. El destino del hombre pobre, ése es el único destino que está escrito [...] Será siempre pobre [...] El destino del hombre rico lo escribe él mismo (CLGF 154);

-Yo quisiera, - volvió a hablar Cirilo-que no hubiera cielo, ni allá ni aquí [...] Porque el cielo no se ha hecho pa'l negro [...] El cielo se ha hecho solamente pa los blancos. En todas partes el negro vive como condenado (CLGF 182);

— ¿Nojotros? - preguntó Juan Cagua con amargura- Nojotros estaremos mal hoy, mañana, pasado mañana [...] Somos el peje chico (CLGF 183);

En definitiva, el fatalismo y la aceptación de las estructuras de opresión y de explotación que definen las relaciones sociales, económicas y políticas en ese universo, entran en homología con la desigualdad institucional, política y económica heredada de la colonia que han marcado y siguen marcando en algunas instancias, la realidad nacional de la república del Ecuador.

Nelson Estupiñán Bass recurre a distintas estrategias narrativas para ubicar su discurso. Una de ellas es la inserción de un subtexto histórico que se apoya en la Historia Nacional con la incorporación de personajes históricos reales (Eloy Alfaro, Carlos Concha). Pese a que no ocupen el primer plano de la narración, dichos personajes sirven para dar cierta legitimidad al discurso de E. Bass como texto alternativo al oficial, y como respuesta a lo que Miguel Donoso Pareja llama "Violencia Histórica" (18).

El autor utiliza también la yuxtaposición de diferentes géneros literarios como recurso narrativo dentro de la novela. En efecto, en el texto se codean la épica, la poesía, el género epistolar, el relato corto, la narración oral y el cuento maravilloso. Los relatos del Curandero (CLGF 145-157) y de el "Pelacara" (CLGF 124-133), por citar unos ejemplos, "leídos" de noche ante una audiencia presente y activa, son típicos de la literatura tradicional cuyos "textos" sólo "se leían" después de las faenas del día, es decir, de noche, cuando los cuerpos y los espíritus estaban descansando y descansados. En este sentido, Cuando los guayacanes florecian se parece mucho, tanto en su estilo como en su estructura, a la novela africana escrita en lenguas europeas de la primera hora.

Todos esos sub-proyectos culturales que integran el espacio novelístico están encaminados hacia un objetivo narrativo e ideológico específico: superar la fragmentación y la alienación que rige esa realidad, e instalar un espacio de solidaridad no sólo para los oprimidos del mundo que describe Estupiñán Bass, sino también, y en última instancia, con todos los oprimidos del mundo. ${ }^{2}$ En este sentido, el discurso humanista de Estupiñán Bass coincide, social, cultural y políticamente, con el proyecto humanista de los intelectuales negro-africanos de Africa y del Caribe integrantes del movimiento de la Négritude. La resolución final del "Deuxième Congrès des Ecrivains et Artistes Noirs" [Segundo Congreso de los Escritores y Artistas Negros] celebrado en Roma, Italia, en 1959 estipulaba que los intelectuales negroafricanos tenían un trabajo y una misión sagrada, y que debían enmarcar sus actividades culturales dentro de

${ }^{2}$ El 8 de mayo de 1998, la Asamblea Nacional Constituyente del Ecuador decidió no reconocer que el Ecuador es un estado plurinacional. En la justificación de su voto, los diputados dijeron que reconocer que Ecuador es un país formado por varias nacionalidades traería la desunión. Véase Nota de la Agencia Informativa Pulsar (via Internet) del 8 de mayo de 1998. 
[...] le grand mouvement de la libération de leurs peuples particuliers, sans perdre de vue la solidarité que doit unir tous ceux, individus et peuples, qui combattent por la liquidation de la colonisation et de ses séquelles, comme tous ceux qui dans le monde luttent pour le progrès et la liberté (387). ${ }^{3}$

Dentro de ese orden de ideas, ambos discursos no sólo coinciden en su proyecto de denuncia y de lucha contra el ciclo de opresión y de agresión al cuerpo negro y de los grupos periféricos en general, sino que su mensaje adquiere un valor universal.

Concluyendo, se puede afirmar que la novela de Estupiñán Bass se enmarca dentro del proyecto de reescritura de la Historia Nacional del Ecuador como estado plurinacional. Asimismo, el texto de Estupiñán Bass es un intento de reapropiación y de reafirmación de la realidad social, cultural y política del Ecuador real. Representa también una tentativa de inserción del discurso socio-político y económico de los distintos actores étnicos y nacionales del país marginados hasta entonces, dentro de ese espacio monopolizado por una minoría no representativa. En este sentido, Cuando los guayacanes florecian es una de las máximas expresiones del llamado discurso humanista.

\section{OBRas CitAdas}

Césaire, Aimé. "Pour salver le Tiers Monde". Ferrements. París: Seuil, 1960.

Chiriboga, Argentina. "Raíces africanas en la nacionalidad ecuatoriana". El negro en la historia. Raices Africanas en la Nacionalidad Ecuatoriana. Guayaquil: Centro Cultural Afroecuatoriano, 1992. 129-139.

Corrales Pascual, Manuel. Situación del relato ecuatoriano. Cincuenta opiniones y una discusión. Quito: Centro de Publicaciones de la Pontificia Universidad Católica del Ecuador, 1977. 71-77.

Cubena (Carlos Guillermo Wilson). Chombo. Miami: Ediciones Universal, 1981.

Donoso Pareja, Miguel. Sin ánimo de ofender. Guayaquil: Vicerrectorado Académico de la Universidad de Guayaquil, 1990.

Estupiñan Bass, Nelson. Cuando los guayacanes florecían. [1954]. Quito: Libresa, 1990. Handelsman, Michael. "Lo afro, la costa y la plurinacionalidad del Ecuador". AfroHispanic Review (Spring, 1997): 16-24.

"Ubicando la literatura afro-ecuatoriana en el contexto nacional: ilusion o realidad?". Afro-Hispanic Review 12/1 (Spring, 1993): 42-47.

\footnotetext{
${ }^{3}$ En este mismo orden de ideas, el poeta martiniqués Aimé Césaire, uno de los fundadores del movimiento négritude, escribía:

Notre Afrique est une main hors du ceste

c'est une main droite, la paume devant,

et les doigts bien serrés;

C'est une main tuméfiée,

une-blesse-main-ouverte,

tendue,

brunes, jaunes, blanches,

à toutes mains, à toutes les mains blessées,

du monde ("Pour salver le Tiers Monde" 85).
} 
Jackson, Richard. "The Human Legacy of Black Latin American Literature". CLA Journal XXX/2 (December, 1986): 154-170.

Black Literature and Humanism in Latin America. Athens/Londres: The University of Georgia Press, 1988.

Ortiz, Adalberto. Juyungo. Estella (Navarra, España): Salvat Editores, 1982.

Pollack-Eltz, Angelina. La familia negra en Venezuela. Caracas: Monte Ávila Editores, 1976.

“Résolution générale sur l'indépendance et l'unité". Présence Africaine 24-25 (février-mai 1959).

Whitten, Norman E. Black Frontiersmen: A South American Case. Nueva York: John Wiley \& Sons, 1974.

Zapata Olivella, Manuel. Changó el Gran Putas ( $1^{\text {a }}$ edición crítica). Santafé de Bogotá: Rei Andes Lta., 1992. 
